Check for updates

Cite this: RSC Adv., 2019, 9, 36113

Received 29th August 2019

Accepted 14th October 2019

DOI: $10.1039 / c 9 r a 06873 b$

rsc.li/rsc-advances

\section{Effect of Fe ion implantation on the thermoelectric properties and electronic structures of $\mathrm{CoSb}_{3}$ thin films}

\author{
Anha Masarrat, ${ }^{\mathrm{ab}}$ Anuradha Bhogra, ${ }^{\mathrm{a}}$ Ramcharan Meena, ${ }^{a}$ Manju Bala, \\ Ranveer Singh, ${ }^{d}$ Vineet Barwal, ${ }^{\text {e }}$ Chung-Li Dong, (D) ${ }^{f}$ Chi-Liang Chen, (D) ${ }^{g}$ T. Som, ${ }^{d}$ \\ Ashish Kumar, ${ }^{a}$ A. Niazi ${ }^{\mathrm{b}}$ and K. Asokan (D) *a
}

\begin{abstract}
In the present study, thin films of single-phase $\mathrm{CoSb}_{3}$ were deposited onto $\mathrm{Si}(100)$ substrates via pulsed laser deposition (PLD) method using a polycrystalline target of $\mathrm{CoSb}_{3}$. These films were implanted by $120 \mathrm{keV} \mathrm{Fe-}$ ions with three different fluences: $1 \times 10^{15}, 2.5 \times 10^{15}$ and $5 \times 10^{15}$ ions per $\mathrm{cm}^{2}$. All films were characterised by X-ray diffraction (XRD), Raman spectroscopy, atomic force microscopy (AFM), Rutherford backscattering (RBS) spectrometry and X-ray absorption spectroscopy (XAS). XRD data revealed that the ion implantation decreased the crystalline nature of these films, which are recovered after the rapid thermal annealing process. The Seebeck coefficient $S$ vary with the fluences in the temperature range of $300 \mathrm{~K}$ to $420 \mathrm{~K}$, and is found to be highest (i.e., $254 \mu \mathrm{V} \mathrm{K}-1$ ) at $420 \mathrm{~K}$ for the film implanted with $1 \times 10^{15}$ ions per $\mathrm{cm}^{2}$. The high $S$ and low resistivity lead to the highest power factor for the film implanted with $1 \times 10^{15}$ ions per $\mathrm{cm}^{2}$ (i.e., $700 \mu \mathrm{W} \mathrm{m} \mathrm{m}^{-1} \mathrm{~K}^{-2}$ ) at $420 \mathrm{~K}$. The changing of the sign of $S$ from negative for the pristine film to positive for the Fe-implanted samples confirm that the Fe ions are electrically active and act as electron acceptors by replacing the Co atoms. XAS measurements confirm that the Fe ions occupied the Co site in the cubic frame of the skutterudite and exist in the $3+$ oxidation state in this structure.
\end{abstract}

\section{Introduction}

Skutterudites have gained considerable attention in the field of thermoelectrics because of their open structure and their applications, such as in the harvesting of waste heat generated in industries and thermoelectric refrigeration. ${ }^{1}$ An efficient thermoelectric material must have low electrical resistivity $(\rho)$, low thermal conductivity $(\kappa)$ and a high Seebeck coefficient $(S)$ related by a dimensionless quantity known as the figure of merit, $z T=S^{2} T / \rho \kappa$, where $\kappa$ is the lattice thermal conductivity that is the sum of $\kappa_{\mathrm{el}}$ (heat conducted by carriers) and $\kappa_{\text {lat }}$ (from the lattice). ${ }^{2}$ The enhancement in $z T$ can be done either by increasing the power factor $S^{2} / \rho$ or by decreasing $\kappa . \mathrm{CoSb}_{3}$ is a low band gap skutterudite compound semiconductor with high $S$ and high carrier mobility. ${ }^{3}$ It has a cubic structure with the formula of $\mathrm{MX}_{3}$, where $\mathrm{M}$ is a metal ion, such as $\mathrm{Co}, \mathrm{Rh}$, and

anter University Accelerator Centre, Aruna Asaf Ali Marg, New Delhi-110067, India. E-mail: asokaniuac@gmail.com

${ }^{b}$ Department of Physics, Jamia Millia Islamia, New Delhi-110025, India

'Department of Physics \& Astrophysics, University of Delhi, New Delhi-110007, India ${ }^{d}$ Institute of Physics, Bhubaneswar-751005, India

${ }^{e}$ Department of Physics, Indian Institute of Technology Delhi, New Delhi-110016, India

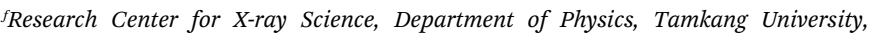
Tamsui 251, Taiwan

${ }^{g}$ National Synchrotron Radiation Research Centre, Hsinchu, Taiwan
Ir, and $\mathrm{X}$ is any metalloid (such as As and $\mathrm{Sb}$ ). Of the eight subcubes in a cubic unit cell, two cubes are voids that can accommodate guest atoms and rattle inside. ${ }^{2}$ Among different skutterudites, $\mathrm{CoSb}_{3}$ shows the best thermoelectric properties as it owns excellent electronic properties, ${ }^{\mathbf{1 , 4 5}}$ although its use in practical applications is limited due to its high lattice thermal conductivity. ${ }^{6}$ However, $\kappa$ can be decreased by filling the voids with rattler atoms, ${ }^{7}$ by nanostructuring ${ }^{8,9}$ or by ion implantation. ${ }^{10}$ Ion implantation is one of the novel ways for modifying the electronic and thermoelectric properties of materials. ${ }^{11,12}$ During ion implantation, doping can be done in a controlled way that enhances the electrical conductivity by increasing the carrier concentration. Simultaneously, it can affect the lattice thermal conductivity by creating lattice defects and disorders. By ion implantation, the void can be filled or occupy the Co or $\mathrm{Sb}$ sites that act as electron donors or acceptors, leading to $\mathrm{p}$ and n-type semiconductors. ${ }^{11,12}$ These dopants can also act as phonon scattering centres and help in reducing the lattice thermal conductivity. Ion implantations by $\mathrm{Fe}^{13-15} \mathrm{Ni}^{16}$ or light ions (such as $\mathrm{B}$ or $\mathrm{C}$ ions) are expected to occupy the $\mathrm{Co}$ or $\mathrm{Sb}$ sites, whereas metals such as Th, $\mathrm{Ur}, \mathrm{La}^{6,7} \mathrm{Eu}^{17}$ or $\mathrm{Ce}^{18,19}$ ions are expected to occupy voids and rattle inside. Such rattling is expected to dramatically reduce the lattice thermal conductivity. Nolas et al. ${ }^{20}$ studied the thermoelectric properties on bulk Ybfilled skutterudite and found $z T$ to be close to 1 at $600 \mathrm{~K}$ for $\mathrm{Yb}_{0.19} \mathrm{Co}_{4} \mathrm{Sb}_{12}$. Wang et al. ${ }^{21}$ reported a high $z T$ of 1.5 at $850 \mathrm{~K}$ for 
$\mathrm{Yb}_{0.3} \mathrm{Co}_{4} \mathrm{Sb}_{12}$, which is the highest filled value for single filled $\mathrm{Co}_{4} \mathrm{Sb}_{12}$. Shi et al. ${ }^{22}$ investigated multi-filled skutterudite bulk materials and was able to achieve a high $z T$ of 1.7 at $850 \mathrm{~K}$. Doping with Fe creates three holes per defect, which reduces the thermal conductivity and also changes the electronic properties of $\mathrm{CoSb}_{3}{ }^{23}$ Katsuyama et al. found that the presence of a second phase in the Co-Fe-Sb ternary system enhanced the figure of merit by suppressing the electrical resistivity and thermal conductivity. ${ }^{24} \mathrm{Kim}$ et al. showed that $\mathrm{Co}_{0.7} \mathrm{Fe}_{0.3} \mathrm{Sb}_{3}$ samples have a thermal conductivity value at around $0.03 \mathrm{~W} \mathrm{~m}^{-1} \mathrm{~K}^{-1}$ and $S$ value of $114 \mu \mathrm{V} \mathrm{K}^{-1}$ at $700 \mathrm{~K}^{25}$ For the skutterudites to be used in device applications, it is necessary to find such promising "bulk" properties in the thin films of skutterudite. Savchuk et al. ${ }^{26}$ studied the structural and transport properties of the n-type polycrystalline $\mathrm{CoSb}_{3}$ thin films grown on oxidised $\mathrm{Si}(100)$ and on $\mathrm{Al}_{2} \mathrm{O}_{3}$ substrates by de magnetron sputtering and obtained a $S$ value of $-250 \mu \mathrm{V} \mathrm{K}^{-1}$ at $\sim 550 \mathrm{~K}$ for both substrates and a thermal conductivity of $3 \mathrm{~W}(\mathrm{mK})^{-1}$ at room temperature. Daniel et al. ${ }^{27}$ studied the thermoelectrical properties of $\mathrm{CoSb}_{3}$ thin films deposited by molecular beam deposition at different substrate temperatures, and showed that the films exhibited bipolar conduction behaviour indicated by a positive Hall constant and a negative $S$. Kumar et al. $^{28}$ studied the thermoelectric properties of In and Yb-doped polycrystalline thin films prepared by PLD and obtained the highest power factor of $0.68 \mathrm{~W}(\mathrm{mK})^{-1}$ at $\sim 700 \mathrm{~K}$. In yet another study, ${ }^{29}$ they reported on the lattice dynamics and thermoelectric properties of the above compounds on different substrates at an elevated temperature, and found that the In and $\mathrm{Yb}$ dopants occupy the cage sites in the skutterudite lattice. Suchitra et al. ${ }^{30}$ studied the incorporation of $\mathrm{MoS}_{2}$ nanosheets in a $\mathrm{CoSb}_{3}$ matrix and reported a $z T$ of 0.53 at $600 \mathrm{~K}$ for the $\mathrm{CoSb}_{3} / \mathrm{MoS}_{2}$ nanocomposite containing $3 \mathrm{wt} \%$ of $\mathrm{MoS}_{2}$, which is 4 times higher than that for the pristine sample. Recent studies by Bala et al. ${ }^{\mathbf{1 1}}$ found an enhancement in the thermoelectric power due to $\mathrm{Ni}$ ion implantation. However, there is no literature found on the studies of doping of $\mathrm{Fe}$ on $\mathrm{CoSb}_{3}$ by the ion implantation method. Among the thin film deposition techniques that have been carried out for the deposition of pure phase $\mathrm{CoSb}_{3}$ are the solvothermal, $^{31}$ RF sputtering, ${ }^{32,33}$ pulsed laser deposition (PLD) $)^{34-37}$ and DC sputtering. ${ }^{26}$ Of these techniques, PLD has proven to be one of the well-suited methods for the deposition of $\mathrm{CoSb}_{3}$ films with proper stoichiometry.

The present study focuses on the morphological, structural, electrical and thermoelectric properties of the Fe ion-implanted $\mathrm{CoSb}_{3}$ thin films deposited by PLD. Further, X-ray absorption spectroscopy has been used to understand the local electronic structures of these Fe-implanted $\mathrm{CoSb}_{3}$ samples.

\section{Experimental details}

The bulk $\mathrm{CoSb}_{3}$ target was prepared by the solid-state reaction method. High purity Co and Sb powders (Alfa-Aesar, 99.98\%) were mixed in a stoichiometric ratio to make a 1 inch target. The mixed powders were sealed in an evacuated quartz tube $\left(<10^{-4}\right.$ torr $)$ and placed in a programmable furnace. The temperature was increased to $1323 \mathrm{~K}$ in $6 \mathrm{~h}$, and then held for
$24 \mathrm{~h}$. It was then allowed to cool to $923 \mathrm{~K}$ in $48 \mathrm{~h}$. It was held at the same temperature for $72 \mathrm{~h}$, and then allowed to cool naturally to room temperature. The polycrystalline material was ground for $3 \mathrm{~h}$ and then pelletised with a 1 inch diameter pellet. It was annealed several times under an Ar gas environment. The target was brittle and had a dark grey metallic lustre. The structure and composition of the target was determined by powder X-ray diffraction (XRD). The films were deposited onto $\mathrm{Si}(100)$ substrates using the PLD system from M/S Excel Instruments, Mumbai. The PLD growth chamber was evacuated to a base pressure of $1.5 \times 10^{-7}$ torr. The deposition was done in the presence of Ar gas with a working pressure of $1.3 \times 10^{-2}$ mbar. The presence of Ar gas during deposition is expected to provide a better thermalisation of the species in the ablation plume. ${ }^{17}$ During the deposition, the target was continuously rotated for the uniform ablation of the target surface to obtain uniformity in the deposited films. The target-to-substrate distance was kept fixed at $6 \mathrm{~cm}$. The substrates were maintained at a temperature of $523 \mathrm{~K}$ during deposition. The substrates were held onto the substrate holder by Ag paste. Reports suggested that the use of Ag paste in sticking the substrates helps in reducing the isotropic compressive stress that causes blistering of the $\mathrm{CoSb}_{3}$ films. ${ }^{37}$ The cumulative effects of the large target-substrate distance, the presence of Ar gas, and the use of Ag paste ensured that all the grown films were free of blistering. A KrF excimer laser $(248 \mathrm{~nm})$ (Coherent Inc.) with a pulse duration of $20 \mathrm{~ns}$ and fixed repetition rate of $10 \mathrm{~Hz}$ was used for ablation. A laser fluence of $184 \mathrm{~mJ}$ per pulse (corresponding to an energy density of $4.6 \mathrm{~J} \mathrm{~cm}^{-2}$ ) was used. After optimisation, the number of shots was fixed to $7272(250 \mathrm{~nm})$. It should be noted that the above-mentioned thickness is only the nominal thickness using surface profilometry. The deposited films were then implanted with $120 \mathrm{keV}$ Fe ions using the Negative Ion Implanter facility of IUAC New Delhi with three different fluences: $1 \times 10^{15}, 2.5 \times 10^{15}$ and $5 \times 10^{15}$ ions per $\mathrm{cm}^{2}$. The implantation was carried out at room temperature with the vacuum maintained at $10^{-6}$ torr. All films were then annealed using the rapid thermal annealing (RTA) technique. The RTA was done for $2 \mathrm{~min}$ at $873 \mathrm{~K}$ under Ar gas. For convenience hereafter, the pristine film will be referred to as $\mathrm{P}$; the rapid annealed film as PA; the films $1 \times 10^{15}, 2.5 \times 10^{15}$ and $5 \times$ $10^{15}$ as $\mathrm{I}_{1 \mathrm{E} 15}, \mathrm{I}_{2.5 \mathrm{E} 15}$ and $\mathrm{I}_{5 \mathrm{E} 15}$, respectively; and the implanted (but rapid-annealed) samples as $\mathrm{I}_{1 \mathrm{E} 15} \mathrm{~A}, \mathrm{I}_{2.5 \mathrm{E} 15} \mathrm{~A}$ and $\mathrm{I}_{5 \mathrm{E} 15} \mathrm{~A}$. The structural characterizations were performed using grazing incidence X-ray diffraction (GIXRD) at $1^{\circ}$ with the Philips X'pert PRO (Model PW 3040) diffractometer. The micro Raman measurements were conducted using a Micro Raman spectroscopy system (m-RS, Renishaw, UK). The reflectance was examined by a UV-vis NIR spectrophotometer (Shimadzu3101PC, Japan) using unpolarized light. Rutherford backscattering (RBS) spectrometry was performed using the $1.7 \mathrm{MV}$ tandem accelerator facility with $2 \mathrm{MeV} \mathrm{He}^{+}$ions at a scattering angle of $165^{\circ}$ at IUAC, New Delhi for compositional and depth profile studies. The data were analysed using the Rutherford Universal Simulation Program (RUMP). AFM was employed to study the surface morphology using the MultiMode® 
scanning probe microscope (Bruker) in tapping mode. The electrical resistivity $(\rho)$ and the Seebeck coefficient $(S)$ were measured by the four-probe method and the bridge method, ${ }^{38}$ respectively, in the temperature range from $300 \mathrm{~K}$ to $400 \mathrm{~K}$. The soft X-ray absorption spectroscopy (XAS) measurements at the Co L- and Fe L-edges were performed at the BL20A1 HSGM beamline, $\mathrm{Sb} \mathrm{L}_{3}$-edge was performed at the 16A1 Tender X-ray absorption beamline, and the Fe K edge was performed at the 17C1 beamline of the National Synchrotron Radiation Research Centre (NSRRC) in Taiwan. The spectra at the Fe and Co $\mathrm{L}_{2,3}$-edges were recorded in the total electron yield (TEY) mode, while the $\mathrm{Sb} \mathrm{L}_{3^{-}}$and Fe K-edges were recorded in the total fluorescent yield (TFY) mode with a photon energy resolution of $0.3 \mathrm{eV}$.

\section{Results and discussion}

The structure and phase of the PLD-deposited films were determined by GIXRD. Fig. 1 shows the GIXRD pattern of $P$, $\mathrm{PA}, \mathrm{I}_{1 \mathrm{E} 15}, \mathrm{I}_{1 \mathrm{E} 15} \mathrm{~A}, \mathrm{I}_{2.5 \mathrm{E} 15}, \mathrm{I}_{2.5 \mathrm{E} 15} \mathrm{~A}, \mathrm{I}_{5 \mathrm{E} 15}$, and $\mathrm{I}_{5 \mathrm{E} 15} \mathrm{~A}$. The pristine as-deposited films were polycrystalline and single phase in nature, and the indexing of the peaks were done based on the simple cubic structure of $\mathrm{CoSb}_{3}$ (JCPDS 19-0336). Due to ion implantation, the films became amorphized and regained their crystallinity after the RTA process under Ar atmosphere. In order to obtain electrically active doped regions, the implanted material needs to be annealed to restore the crystal lattice and relocate the implanted atoms onto substitutional sites where they can become electrically active. During the regrowth of the amorphous layers in $\mathrm{CoSb}_{3}$, the implanted dopant can take up substitutional lattice positions or accommodate in void spaces depending on the dopant concentration and size of the dopant atom. Due to the high $S_{\mathrm{n}}$ (nuclear

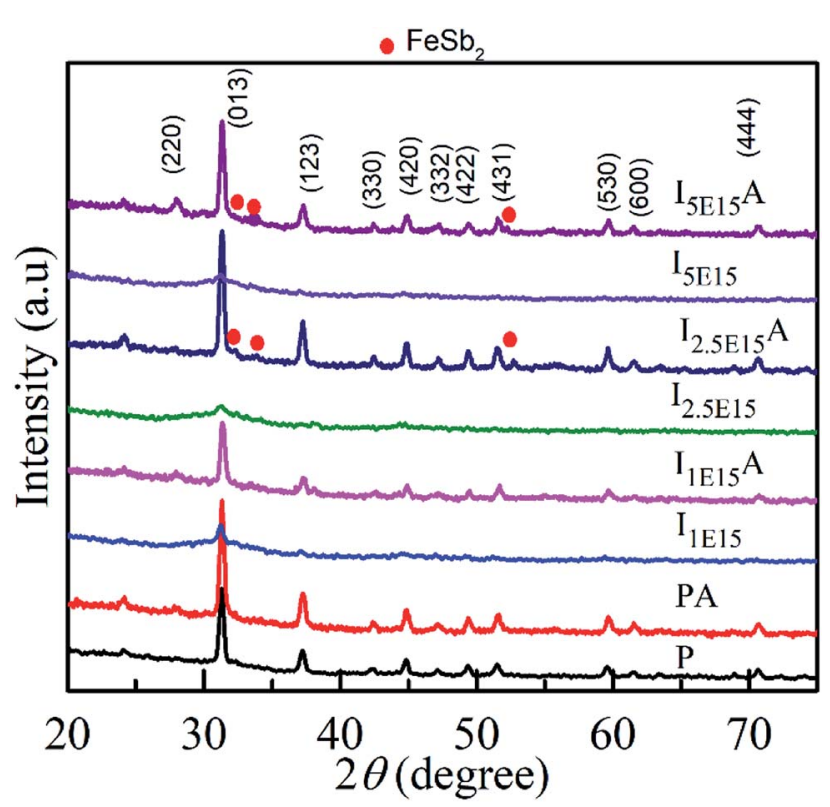

Fig. 1 XRD pattern of the $\mathrm{COSb}_{3}$ thin films: P, PA, $I_{1 E 15}, I_{1 E 15} A, I_{2.5 E 15}$, $I_{2.5 E 15} A, I_{5 E 15}$, and $I_{5 E 15} A$. Note that after RTA, recrystallization is evident. energy loss, $106 \mathrm{eV} \mathrm{nm}{ }^{-1}$ ) during implantation, extended damages lead to the creation of vacancies through nuclear collisions. The vacancies created as calculated by the TRIM ${ }^{39}$ (transport of ions in matter) software are 2213.8 per Fe ion. The projected range is $60 \mathrm{~nm}$ with a straggling of $30 \mathrm{~nm}$. Based on this, it was found that a $\sim 90 \mathrm{~nm}$ thick layer is amorphized. The remaining crystalline layer enables the recrystallisation of films after the RTA process. There were no traces of secondary phases of $\mathrm{Co}$ or $\mathrm{Sb}$ ions within the detection limit of the samples (JCPDS 03-0717). This $\mathrm{FeSb}_{2}$ impurity has been reported earlier at higher doping concentrations. ${ }^{24}$ Fig. 2 shows the Rietveld refined pattern of the pristine sample. All samples crystallized in the body centred cubic space group $\operatorname{Im} \overline{3}$ (\#204). As obtained after refinement, the unit cell volume was 73.87 $\mathrm{nm}^{3}$. The Co metal ions are located at the $8 \mathrm{c}$ sites $(1 / 4,1 / 4,1 /$ 4 ), while the pnictogen atom Sb occupied the $24 \mathrm{~g}$ sites $(0, y, z)$. All the diffraction peaks match well with the reference structure, indicating the phase purity of the pristine sample. After refinement, the lattice parameter is $9.04 \AA$ for the pristine sample. This value is in close agreement with the reported value of 9.0385 A (JCPDS 19-0336).

Christensen et $a .^{40}$ also reported a decrease in the lattice parameter after Fe doping. However, they did not observe a clear trend in the lattice parameter values. The lattice parameter and atomic coordinates obtained from these refinements were used as inputs in the Vesta ${ }^{\mathbf{4 1}}$ program to visualise the crystal structure of the pristine sample. Fig. 2 shows the crystal structure of $\mathrm{CoSb}_{3}$. In this structure, the blue dashed lines show the $\mathrm{CoSb}_{6}$ octahedron and the region by the green dashed lines forms the void. The bonding between the atoms is mainly covalent in nature. The distance between the two metal atoms (Co-Co) is large so these ions do not create

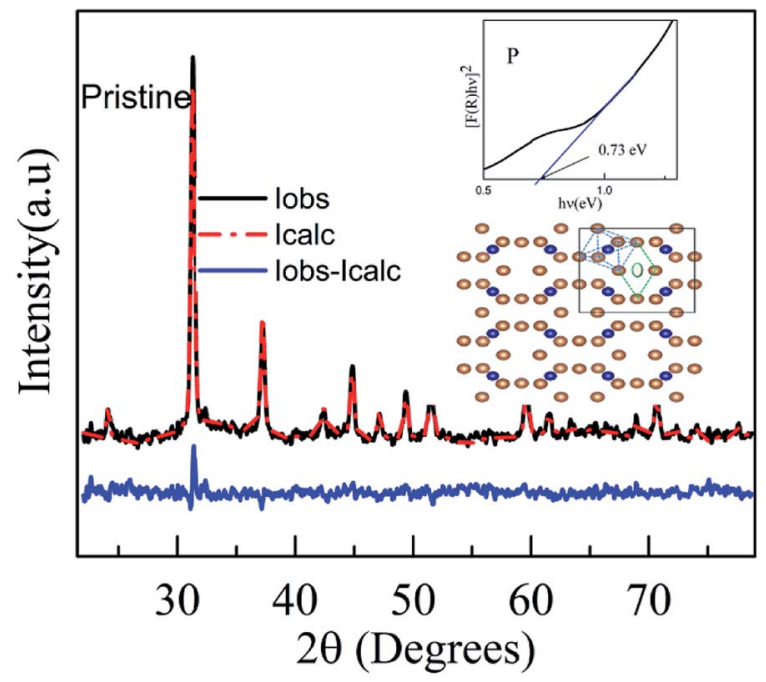

Fig. 2 Rietveld refined pattern of the pristine sample. The inset (right side) shows the Tauc plot of the pristine $\mathrm{CoSb}_{3}$ sample. The structure with blue dashed lines forms the $\mathrm{CoSb}_{6}$ octahedron and the one with green dashed lines depicts the void. The brown-coloured atoms represent $\mathrm{Sb}$, the blue ones are $\mathrm{Co}$ and the grey-coloured atom shows the guest atom. 
a bonding; hence, the bonding occurs between $\mathrm{Sb}-\mathrm{Sb}$ (pnictogen atoms), creating the $\mathrm{Sb}_{4}$ rings and pnictogen and metal atom bonding (Co-Sb). The bond lengths, as obtained from the Rietveld refinement data, are Co-Sb (2.531 A), Sb-Sb short pair $(2.855 \AA)$ and Sb-Sb long pair (3.43 $\AA$ ). It is comparable with the values given in the literature for unfilled $\mathrm{CoSb}_{3}{ }^{42}$ $\mathrm{CoSb}_{3}$, a narrow band-gap semiconductor, has an energy gap that lies in the far-infrared region. However, the optical characterization in the present work is limited to the UV-visible region. The optical properties of the $\mathrm{CoSb}_{3}$ thin film was analysed by UV-visible reflectance spectra. The band gap was estimated using the Kubelka-Munk (KM) equation and it was found to be $0.73 \mathrm{eV} .^{32}$ Anno et al. have reported a band gap energy of $0.9 \mathrm{eV} \cdot{ }^{32}$ However, it was found that the optical band gap varied from 0.5 to $0.9 \mathrm{eV}^{33}$

The Raman spectra of P, PA, $\mathrm{I}_{1 \mathrm{E} 15} \mathrm{~A}, \mathrm{I}_{2.5 \mathrm{E} 15} \mathrm{~A}$ and $\mathrm{I}_{5 \mathrm{E} 15} \mathrm{~A}$ thin films measured at $300 \mathrm{~K}$ are shown in Fig. 3. The as-deposited $\mathrm{P}$ film did not show any characteristic Raman modes of $\mathrm{CoSb}_{3}$. However, after RTA, five out of eight Raman active modes are observed in all implanted and annealed samples. All these modes were assigned on the basis of group theory and the $\mathrm{CoSb}_{3}$ crystallite reported by Nolas et al. ${ }^{20}$ These peaks show a small shift when compared with that reported in the literature (Table 1). ${ }^{19}$

The Raman active modes in the $\mathrm{CoSb}_{3}$ structure did not include any motion of the Co metal sub-lattice atoms; rather, these show the relative motion of the $\mathrm{Sb}$ atom with respect to each other so that the centre of mass of Sb in the unit cell does not change. The matching of the phonon frequency of all the implanted films with the literature further confirms the formation of the skutterudite structure. This implies that the Fe ions are implanted at the Co sites and not in the Sb sites. There is a small broadening observed in all implanted samples. The broadening of the peaks may be due to phonon-phonon interactions. Another possible mechanism for such broadening is the disorder caused by the random placement of Fe ions during ion implantation.

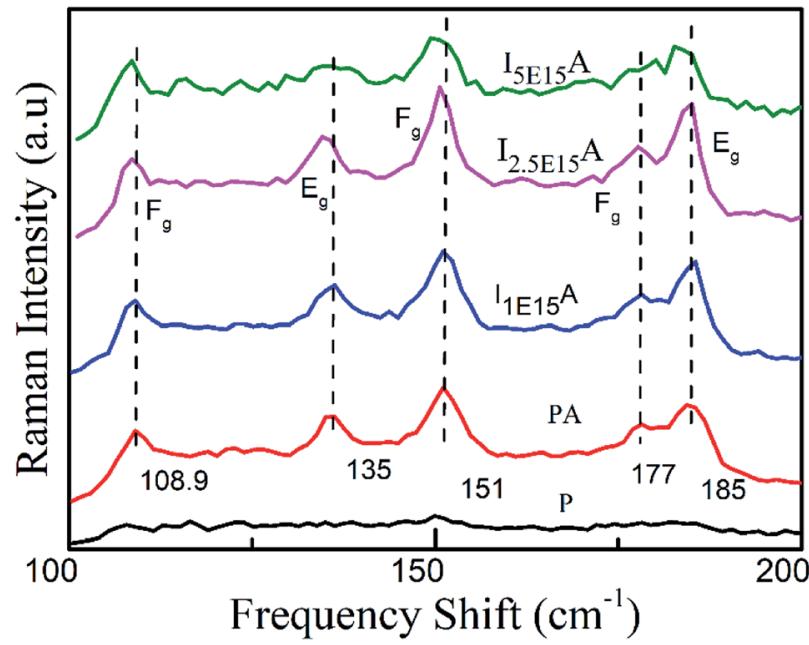

Fig. 3 Raman spectra of the $\mathrm{CoSb}_{3}$ thin films: $P, P A, I_{1 E 15} A, I_{2.5 E 15} A$, and $I_{5 E 15} A$. At the highest ion fluence, broadening is observed.
If some of the Fe ions are trapped in the voids created by the $\mathrm{Sb}$ atoms, they might rattle inside these voids. This rattling of the Fe ions gives rise to the fluctuating bonding of the $\mathrm{Sb}$ bonds that makes the boundary of the voids. This might lead to a slight broadening of the vibrational energies of the $\mathrm{Sb}$ rings. ${ }^{43}$ The spectral assignment has been done by comparing the vibrational energies from the literature. ${ }^{43}$ The $E_{g}$ peaks at $135 \mathrm{~cm}^{-1}$ (theoretically predicted at $139 \mathrm{~cm}^{-1}$ ) and $184 \mathrm{~cm}^{-1}$ depict the elongation of all sides of one rectangle, while shortening of all sides of another one. ${ }^{43}$ The $F_{g}$ peak at $151 \mathrm{~cm}^{-1}$ (predicted at $157 \mathrm{~cm}^{-1}$ ) depicts the rotation of the rectangle about an axis parallel to one side. The $\mathrm{F}_{\mathrm{g}}$ weak peak at $176 \mathrm{~cm}^{-1}$, which is theoretically predicted at $178 \mathrm{~cm}^{-1}$, depicts the out of plane shear motion of two atoms of a rectangle along a diagonal. All peaks are in good agreement with the theoretical calculations. ${ }^{44}$

Fig. 4 shows the $2 \mathrm{D}$ and $3 \mathrm{D}$ AFM images of $\mathrm{P}, \mathrm{I}_{1 \mathrm{E} 15} \mathrm{~A}$, $\mathrm{I}_{2.5 \mathrm{E} 15} \mathrm{~A}$, and $\mathrm{I}_{5 \mathrm{E} 15} \mathrm{~A}$ films. The suitable parameter used to characterise the surface morphology of the thin film is the root mean square (RMS) roughness. From the AFM micrograph, a change in the surface morphology by varying the Fe ion fluence is evident. The RMS surface roughness of $\mathrm{P}$ was $1.68 \mathrm{~nm}$, which increased with ion fluences and reached up to $3.70 \mathrm{~nm}$ for $\mathrm{I}_{2.5 \mathrm{E} 15} \mathrm{~A}$. This increase in the ion fluencies is due to the defects and disorders created by the ion beam during implantation. For $\mathrm{I}_{5 \mathrm{E} 15} \mathrm{~A}$, the roughness decreased to $1.78 \mathrm{~nm}$. It might be because the disorders or defects were annealed out due to local annealing at higher fluence during implantation. The grains of $\mathrm{P}$ were found to be uniform with an average grain size of $72.40 \mathrm{~nm}$, and it increased to $95.56 \mathrm{~nm}$ for $\mathrm{I}_{1 \mathrm{E} 15} \mathrm{~A}$. For the $\mathrm{I}_{2.5 \mathrm{E} 15} \mathrm{~A}$ and $\mathrm{I}_{5 \mathrm{E} 15} \mathrm{~A}$ samples, the grains were found to be agglomerated.

The RBS was performed to confirm the thickness and composition of the $\mathrm{P}, \mathrm{I}_{1 \mathrm{E} 15} \mathrm{~A}, \mathrm{I}_{2.5 \mathrm{E} 15} \mathrm{~A}$, and $\mathrm{I}_{5 \mathrm{E} 15} \mathrm{~A}$ films. Fig. 5 (inset) shows the distribution of the Fe ions in the $\mathrm{CoSb}_{3}$ thin film. The SRIM ${ }^{45}$ (Stopping and Range of Ions in Matter) software was used to calculate the depth distribution of the Fe ions in the $\mathrm{CoSb}_{3}$ thin film. From the figure, it is observed that the depth of the Fe ion is $60 \mathrm{~nm}$ with straggling of $30 \mathrm{~nm}$. Fig. 5 gives the comparison of the $\mathrm{P}, \mathrm{I}_{1 \mathrm{E} 15} \mathrm{~A}, \mathrm{I}_{2.5 \mathrm{E} 15} \mathrm{~A}$, and $\mathrm{I}_{5 \mathrm{E} 15} \mathrm{~A}$ films. It shows that the thickness of the film decreases with an increase in the Fe ion fluence. As calculated by TRIM, the sputtering is 1.45 atoms of Co and 5.67 atoms of $\mathrm{Sb}$ for each implanted $\mathrm{Fe}$ ion. Hence, a few $\mathrm{nm}$ of the film layer was sputtered out, leading to the decrease in the film thickness. The thickness further decreased with the increase in the ion fluences. Fig. 6 shows the simulated RBS spectra and depth profiles of the $\mathrm{P}$ and $\mathrm{I}_{2.5 \mathrm{E} 15} \mathrm{~A}$ films. It shows that the thickness of the $\mathrm{P}$ film was $\sim 250 \mathrm{~nm}$ with the composition of $\mathrm{Co}_{1.2} \mathrm{Sb}_{2.8}$.

Fig. 7(a) gives the variation of resistivity with temperature for the $\mathrm{P}, \mathrm{I}_{1 \mathrm{E} 15} \mathrm{~A}, \mathrm{I}_{2.5 \mathrm{E} 15} \mathrm{~A}$, and $\mathrm{I}_{5 \mathrm{E} 15} \mathrm{~A}$ films from $100 \mathrm{~K}$ to $420 \mathrm{~K}$. The resistivity of all the thin films decreases with the increase in temperature, depicting a typical semiconducting behaviour. However, the resistivity of $\mathrm{P}(\sim 100 \mu \Omega \mathrm{m})$ at $100 \mathrm{~K}$ is quite high compared to that of the bulk sample ${ }^{48}(\sim 8 \mu \Omega \mathrm{m})$ at the same temperature. The approximate grain size of the films was $\sim 70-$ $80 \mathrm{~nm}$ compared to that of the bulk $\mathrm{CoSb}_{3}$ sample $(1-10 \mu \mathrm{m})$. 
Table 1 Peak positions of Raman active modes of the $\mathrm{CoSb}_{3}$ films from the present work are compared with theory. ${ }^{19}$

\begin{tabular}{llll}
\hline Present work $\bar{v}\left(\mathrm{~cm}^{-1}\right)$ & $\mathrm{CoSb}_{3}$ crystallite $\bar{v}\left(\mathrm{~cm}^{-1}\right)$ & $\mathrm{CoSb}_{3}$ theory $\bar{v}\left(\mathrm{~cm}^{-1}\right)$ & Modes assigned \\
\hline 108.9 & 110 & 97 & $\left(\mathrm{~F}_{\mathrm{g}}\right)$ \\
135 & 135 & 139 & $\left(\mathrm{E}_{\mathrm{g}}\right)$ \\
151 & 152 & 150 & $\left(\mathrm{~F}_{\mathrm{g}}\right)$ \\
178 & 179 & 179 & $\left(\mathrm{~F}_{\mathrm{g}}\right)$ \\
184 & 187 & 182 & $\left(\mathrm{E}_{\mathrm{g}}\right)$
\end{tabular}

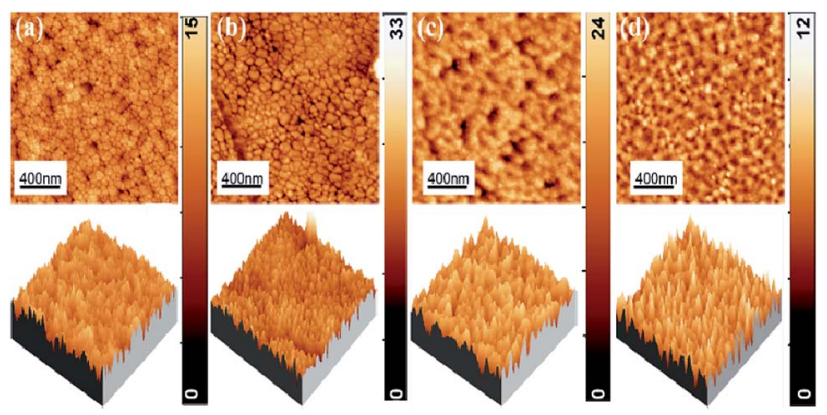

Fig. 4 2D and 3D AFM images of (a) $P$, (b) $I_{1 E 15} A$, (c) $I_{2.5 E 15} A$, (d) $I_{5 E 15} A$ films.

Due to the presence of grain boundaries, the scattering effects are enhanced. The high concentration of structural and surface defects also provides a potential barrier for the electrons and increase the resistivity. The resistivity of all implanted films is low compared to that of the pristine film. The resistivity of $\mathrm{I}_{1 \mathrm{E} 15} \mathrm{~A}$ decreases $\sim 5$ times when compared to that of $\mathrm{P}$ at low temperature $(100 \mathrm{~K})$. It may be due to an increase in the carrier concentration (holes) due to Fe ion implantation. Yang et al. ${ }^{23}$ reported that the hole concentration in the Fe-doped sample is entirely due to the number of vacancies created by the Fe ion on the Co site in the skutterudite. The TRIM calculation shows the

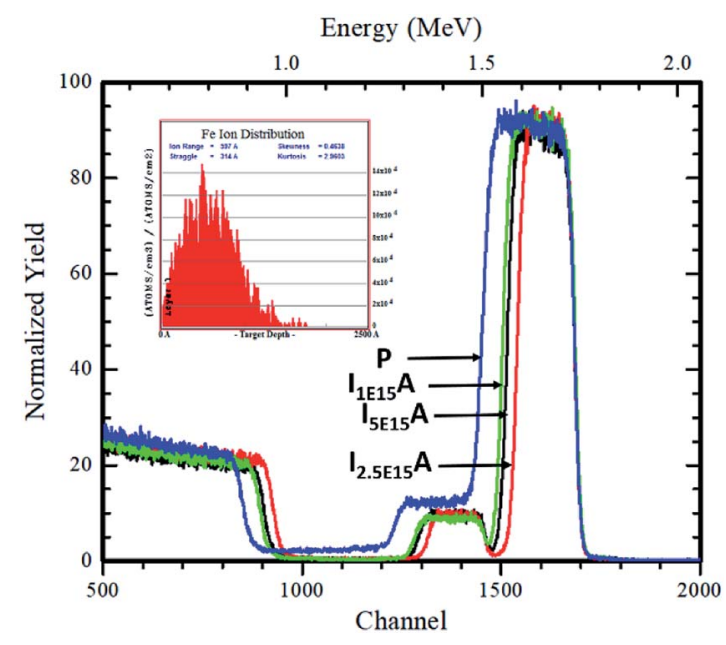

Fig. 5 Comparison of the RBS spectra of $P, I_{1 E 15} A, I_{2.5 E 15} A$, and $I_{5 E 15} A$ films. The inset shows the depth distribution of the implanted Fe ions in the $\mathrm{CoSb}_{3}$ thin films. creation of a large number of vacancies (2213.8 per Fe ion), which lead to the increase in the hole concentrations. This greatly assisted in decreasing the electrical resistivity of the Feimplanted samples. The decrease in resistivity from $\mathrm{P}$ to implanted $\mathrm{I}_{1 \mathrm{E} 15} \mathrm{~A}$ can also be explained on the basis of the grain boundary scattering mechanism. From the AFM data, it is observed that the grain size of $\mathrm{P}$ increases from $72.4 \mathrm{~nm}$ to $95.5 \mathrm{~nm}$ for $\mathrm{I}_{1 \mathrm{E} 15} \mathrm{~A}$. It is generally considered that the samples having a larger grain size must have low electrical resistivity due to the grain boundary scattering mechanism. The resistivity for $\mathrm{I}_{5 \mathrm{E} 15} \mathrm{~A}$ is found to be higher than that for the $\mathrm{I}_{1 \mathrm{E} 15} \mathrm{~A}$-implanted samples. It may be due to the enhancement of carrier scattering at the grain boundaries because of the presence of the $\mathrm{FeSb}_{2}$ grains. During ion implantation, as the Fe ion fluence increases, the number of vacancies created on the Co site (and hence, the hole concentrations) also increases. Simultaneously, the surface and interstitial defects also increase. These defects and dislocations lead to the decreased mobility of the charge carrier across these defects, which in fact increases in the electrical resistivity at higher fluence. Fig. 7(b) shows the variation of $S$ with temperature for $\mathrm{P}, \mathrm{I}_{1 \mathrm{E} 15} \mathrm{~A}, \mathrm{I}_{2.5 \mathrm{E} 15} \mathrm{~A}$, and $\mathrm{I}_{5 \mathrm{E} 15} \mathrm{~A}$ samples from $300 \mathrm{~K}$ to $420 \mathrm{~K}$. The $S$ of the $\mathrm{P}$ sample is negative, indicating n-type conduction. However, for the Fe-implanted system, $S$ is positive and shows a p-type conduction behaviour. It has been reported that intrinsic $\mathrm{CoSb}_{3}$ shows n-type and p-type behaviour, depending on the stoichiometry. If pure $\mathrm{CoSb}_{3}$ is synthesised under Co-rich conditions, its behaviour will be n-type as it creates an excess of electrons in the

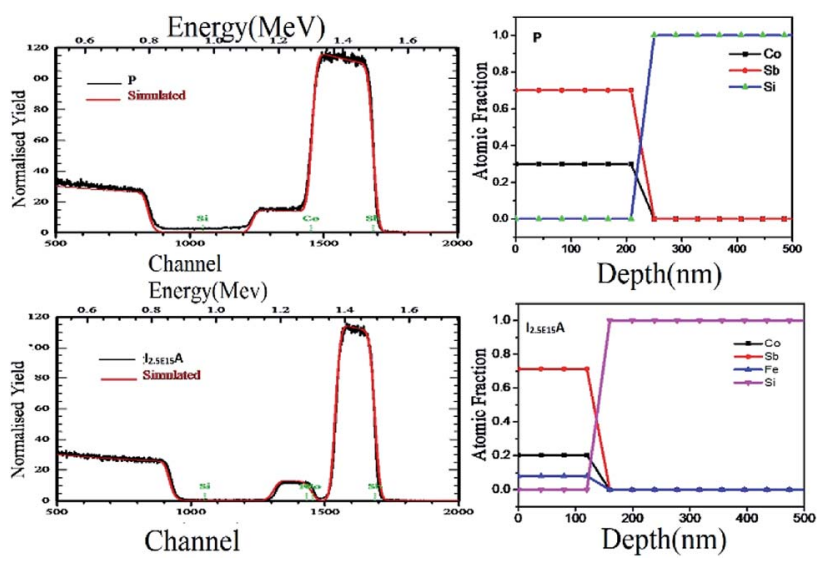

Fig. 6 Simulated RBS spectra and depth profiles extracted from the RBS analysis of $P$ and $I_{2.5 E 15} A$. 

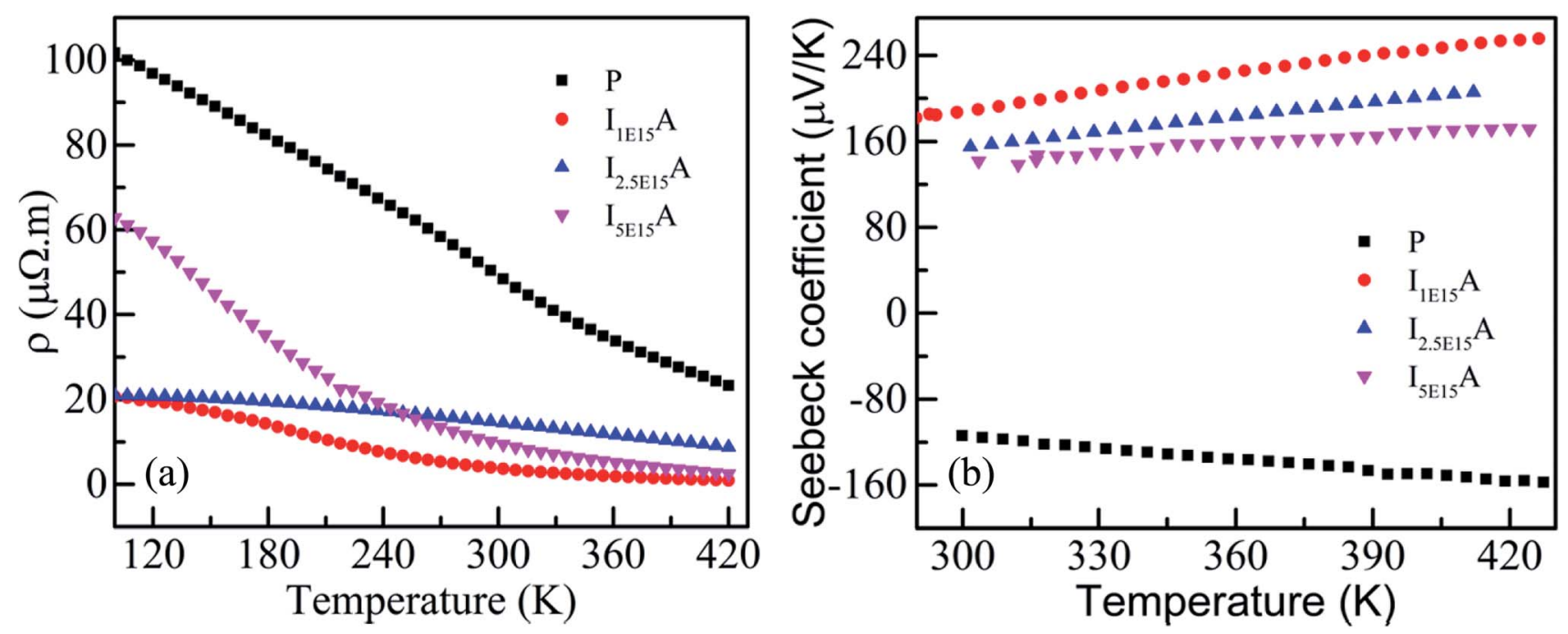

Fig. 7 (a) Resistivity of $P, I_{1 E 15} A, I_{2.5 E 15} A$, and $I_{5 E 15} A$. (b) Seebeck coefficient of $P, I_{1 E 15} A, I_{2.5 E 15} A$, and $I_{5 E 15} A$.

conduction band. If it is synthesised in a Sb-rich environment, it is p-type as this signifies limited Co atoms and leads to the formation of holes in the valence band. In the present study, due to the annealing of films at an elevated temperature of 873 $\mathrm{K}$, some $\mathrm{Sb}$ ions are volatilized out, leading to n-type behaviour. For the Fe-implanted samples, $\mathrm{Fe}\left(4 \mathrm{~s}^{2} 3 \mathrm{~d}^{6}\right)$ possesses one electron less than Co $\left(4 \mathrm{~s}^{2} 3 \mathrm{~d}^{7}\right)$, so it acts as an acceptor when it occupies the Co site; hence, the Fe-implanted $\mathrm{CoSb}_{3}$ displays ptype conduction behaviour. The electrical properties depend on whether the $\mathrm{Fe}$ ion assumes the $\mathrm{Fe}^{2+}\left(3 \mathrm{~d}^{6}\right)$ or $\mathrm{Fe}^{3+}\left(3 \mathrm{~d}^{5}\right)$ state. The P film gives a $S$ value of $-120 \mu \mathrm{V} \mathrm{K}^{-1}$ at room temperature, which increases up to $-157 \mu \mathrm{V} \mathrm{K}^{-1}$ at $420 \mathrm{~K}$. For the Feimplanted sample, the $S$ decreases with increasing Fe fluence. The dependency of $S$ on the carrier concentration $(n)$ is given by the relation:

$$
S=\frac{8 \pi^{2} K_{\mathrm{B}}^{2}}{3 e h^{2}} m T\left(\frac{\pi}{3 n}\right)^{\frac{2}{3}}
$$

Thus, $S$ depends on the carrier concentration and decreases with increasing ion fluence. The $S$ values for $\mathrm{I}_{1 \mathrm{E} 15} \mathrm{~A}, \mathrm{I}_{2.5 \mathrm{E} 15} \mathrm{~A}$, and $\mathrm{I}_{5 \mathrm{E} 15} \mathrm{~A}$ at $420 \mathrm{~K}$ are 245,200 and $158 \mu \mathrm{V} \mathrm{K}^{-1}$, respectively. This is consistent with the results from Yang et al. ${ }^{23}$ that reported a drop in $S$ with the increase in Fe doping. The decrease in $S$ with increasing fluence may be also due to the generation of a large number of defects created during the implantation process. As the Fe ions enter the material, they create defects in the system. The defects can be present in the form of the implanted ions themselves or the creation of either interstitial or vacancy pairs. These interstitial or vacancy pairs arise due to knock-on collisions, either by the incident ion known as a primary collision or by other knocked-on atoms called a secondary collision. This collision cascade results in a highly disordered region including the defects, and these defects increase with increasing ion fluence. Table 2 compares the $S$ and $\rho$ of the present experimental results with that reported in the literature. From the table, it is evident that the $S$ of the Fe ion-implanted sample is around three times higher than that of the Fe-doped bulk sample. Yang et al. ${ }^{23}$ also reported that the heat conduction is reduced due to the creation of vacancies on the Co site due to Fe doping. Thus, there is a possibility of dramatically suppressing the lattice thermal conductivity with Fe ion implantation by increasing the lattice defects, mainly by the creation of vacancies on the Co site of the skutterudite structure. Fig. 8 shows the power factor (P.F. $=S^{2} / \rho$ ) versus temperature from $300 \mathrm{~K}$ to $420 \mathrm{~K}$. The P.F. for the $\mathrm{Fe}$ ionimplanted samples are found to be greater than that for the pristine sample. A highest value of P.F. $=700 \mu \mathrm{W} \mathrm{m}{ }^{-1} \mathrm{~K}^{-2}$ is obtained at $420 \mathrm{~K}$ for the $\mathrm{I}_{1 \mathrm{E} 15} \mathrm{~A}$ sample. The large increase in P.F. can be attributed to the increase in the carrier concentration, high $S$ and low $\rho$ of the Fe ion-implanted samples.

For an in-depth understanding of the structural and electrical properties of the Fe ion-implanted $\mathrm{CoSb}_{3}$, one needs to investigate their electronic structures. Fig. 9 shows the $\mathrm{Co}_{\mathrm{L}^{-}}$edge spectra of the Fe-implanted $\mathrm{CoSb}_{3}$ thin films. These spectra show the splitting of the Co $2 \mathrm{p}$ core-hole spin orbit into the $\mathrm{L}_{3}(\sim 779 \mathrm{eV})$ and $\mathrm{L}_{2}(795 \mathrm{eV})$ edges due to an electron transition from their initial state of $2 \mathrm{p}_{3 / 2}$ and $2 \mathrm{p}_{1 / 2}$ to the unoccupied 3d states hybridized with the Sb $5 \mathrm{p}$ orbital. ${ }^{49}$ The peak positions of the $\mathrm{L}_{3}$-edges for $\mathrm{P}, \mathrm{I}_{1 \mathrm{E} 15} \mathrm{~A}, \mathrm{I}_{2.5 \mathrm{E} 15} \mathrm{~A}$, and $\mathrm{I}_{5 \mathrm{E} 15} \mathrm{~A}$ are almost the same within the resolution of this measurement except for $\mathrm{I}_{2.5 \mathrm{E} 15} \mathrm{~A}$. There is a small shift in the binding energy of $\mathrm{I}_{2.5 \mathrm{E} 15} \mathrm{~A}$, which shows that the chemical state of the Co ion is different compared to that of $\mathrm{P}$. There is no distinct shoulder peak at $777 \mathrm{eV}$ corresponding to the presence of $\mathrm{Co}^{2+}$ impuri$\operatorname{ties}^{50}$ (as in CoO). Further, these spectra show a close resemblance to the $\mathrm{Co}^{3+}$ (low spin) $\mathrm{EuCoO}_{3}$ spectra, ${ }^{50}$ indicating that one can safely rule out the presence of $2+$ valence state. This implies that the Co ion in the $\mathrm{CoSb}_{6}$ octahedron is in the $3+$ valence state..$^{51}$ The line shape of the spectrum strongly depends on the multiplet structure formed by the Co $3 \mathrm{~d}-3 \mathrm{~d}$ and $2 \mathrm{p}-3 \mathrm{~d}$ Coulomb and exchange interactions, and also by the local 
Table 2 Room temperature Seebeck coefficient and resistivity of the present study compared with that from literature (ref. 23, 46 and 47)

\begin{tabular}{|c|c|c|c|}
\hline Sample & & Seebeck coefficient $\left(\mu \mathrm{V} \mathrm{K}{ }^{-1}\right)$ & Resistivity $(\mu \Omega \mathrm{m})$ \\
\hline \multirow[t]{2}{*}{ Bulk } & Undoped single crystal $^{a}$ & 220 & 18.94 \\
\hline & Pristine $\mathrm{CoSb}_{3}{ }^{b}$ & 90 & 7 \\
\hline \multirow[t]{3}{*}{ Thin film } & Pristine $\mathrm{CoSb}_{3}{ }^{c}$ & $\sim-6$ & 3.2 \\
\hline & Pristine $\mathrm{CoSb}_{3}{ }^{d}$ & -120 & 50 \\
\hline & Fe doped (this work) ${ }^{d}$ & 187 & 3 \\
\hline
\end{tabular}

${ }^{a}$ From ref. 46. ${ }^{b}$ From ref. $23 .{ }^{c}$ From ref. $47 .{ }^{d}$ Data from this work.

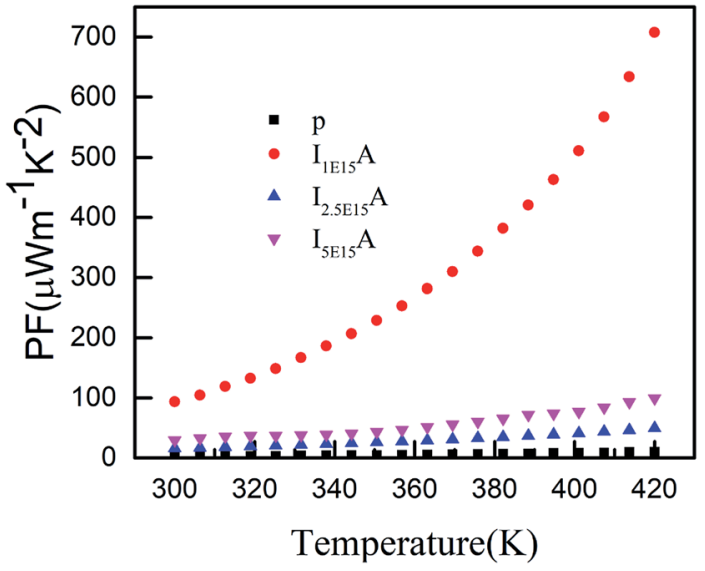

Fig. 8 Power factor of $P, I_{1 E 15} A, I_{2.5 E 15} A$, and $I_{5 E 15} A$.

crystal field and hybridization of the Co metal atom with the $\mathrm{Sb}$ 5p ligands. ${ }^{11}$ Due to similar electronegativity between Fe (1.83), $\mathrm{Co}(1.88)$ and $\mathrm{Sb}$ (2.05), there are four possibilities for the Fe ions to be incorporated into the $\mathrm{CoSb}_{3}$ structure after ion implantation: (i) taking the $\mathrm{Sb}_{12}$ icosahedron voids to form Fefilled $\mathrm{CoSb}_{3}$, (ii) occupying the Co site in the irregular $\mathrm{Sb}_{6}$ octahedron to form $\mathrm{Fe}_{x} \mathrm{Co}_{1-x} \mathrm{Sb}_{3}$, (iii) occupying the $\mathrm{Sb}$ site in the $\mathrm{Sb}_{2} \mathrm{Co}_{2}$ tetrahedron to form $\mathrm{CoFe}_{x} \mathrm{Sb}_{3-x}$ or simultaneously occupying the $\mathrm{Sb}_{12}$ icosahedron voids and (iv) substituting the Co site in the irregular $\mathrm{Sb}_{6}$ octahedron. From the figure, the decrease in the intensity of the $\mathrm{Co}_{\mathrm{L}_{3}}$-edge is observed for the

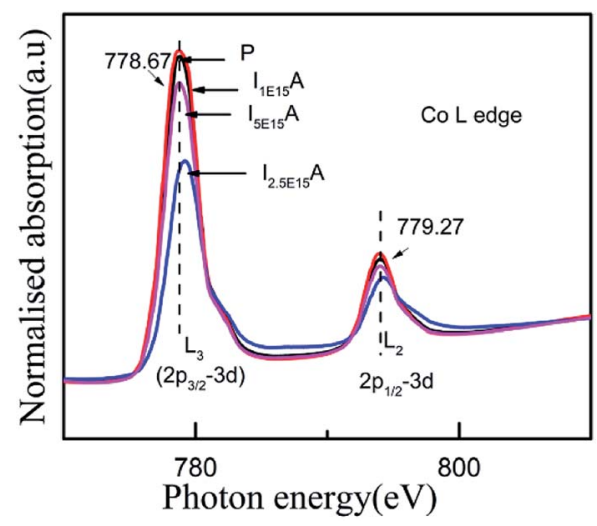

Fig. 9 Co L-edge XANES spectra of the Fe-implanted $\mathrm{CoSb}_{3}$ thin films. implanted films as compared to the pristine sample. This decrease in the intensity in the implanted samples indicates that the Fe ions are filled in the Co site. Hence, it is concluded that the Fe ions occupy the Co site in the $\mathrm{CoSb}_{6}$ octahedra. The spectral shapes are almost similar for all the implanted samples, but the width of the white line decreases on the lower energy side of the $\mathrm{L}_{3}$-edge of $\mathrm{I}_{2.5 \mathrm{E} 15} \mathrm{~A}$. Analysing the full width at half maximum (FWHM) of the spectra, it is observed that the $\mathrm{P}$ sample has a FWHM value of $2.87 \mathrm{eV}$. The FWHM of $\mathrm{I}_{1 \mathrm{E} 15} \mathrm{~A}$ is $3.08 \mathrm{eV}$ and then drops to $2.96 \mathrm{eV}$, maintaining the same value at higher fluences. After ion implantation, the increase in the FWHM also implies the Fe occupancy of the Co site and the local distortion. Fig. 10 shows the $\mathrm{Sb} \mathrm{L}_{3}$-edge of the $\mathrm{CoSb}_{3}$ thin films. The $\mathrm{Sb}_{3}$-edge arises from the transition from the core $2 \mathrm{p}_{3 / 2}$ states to the unoccupied $4 \mathrm{~d}$ and $5 \mathrm{~s}$ states. The pre-peak marked as $\mathrm{S}_{1}$ in the figure at $4136.62 \mathrm{eV}$ is attributed to the $2 \mathrm{p}_{3 / 2}$-to-5s transition. The main absorption peak marked as $\mathrm{S}_{2}$ at higher energy, $4145.91 \mathrm{eV}$, is attributed to the $2 \mathrm{p}_{3 / 2}$-to-5d transitions. ${ }^{52} \mathrm{~A}$ weak shoulder observed in the $\mathrm{Sb}$ powder is absent in the pristine sample and implanted thin films. There is an increase in the intensity of the spectral feature of $\mathrm{S}_{2}$ with Fe ion implantation. Consequently, the Fe implantation in the $\mathrm{CoSb}_{3}$ host matrix changes the charge carrier concentration apart from inducing the structural disorder. In the X-ray Absorption Near Edge Structure (XANES) spectra, the absorption features primarily depend on the unoccupied states in the conduction band. Analysis of the spectral features at $4136.62 \mathrm{eV}$ and $4145.91 \mathrm{eV}$ of the Sb L-edge in $\mathrm{P}$ (pristine $\mathrm{CoSb}_{3}$ ) shows an

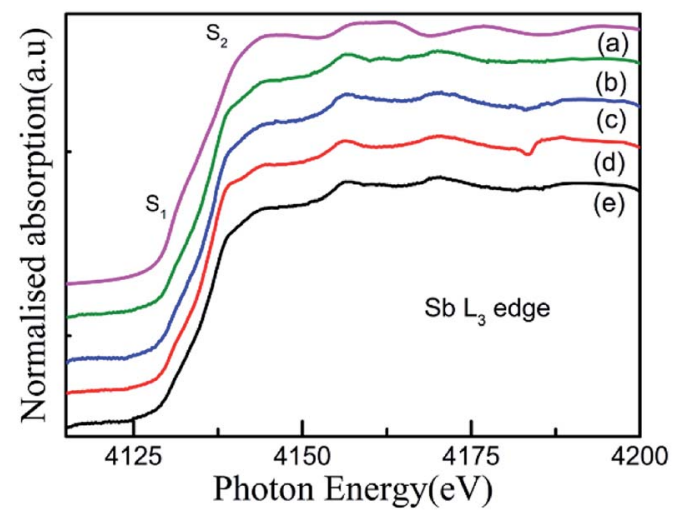

Fig. $10 \mathrm{Sb} \mathrm{L}_{3}$-edge XANES spectra of the (a) Sb powder, (b) $\mathrm{P}$, (c) $I_{5 E 15} \mathrm{~A}$, (d) $I_{2.5 E 15} A$, (e) $I_{1 E 15} A$ thin films. 
increase in the intensities with $\mathrm{Fe}$ ion implantation (for $\mathrm{I}_{2.5 \mathrm{E} 15} \mathrm{~A}$ ), indicating an increase of density of unoccupied Sb $5 \mathrm{p}$ states. Simultaneously, the Co L-edges of $\mathrm{P}$ and $\mathrm{I}_{2.5 \mathrm{E} 15} \mathrm{~A}$ indicate a decrease in the intensities. This implies that there is a charge transfer from $\mathrm{Sb}$ to the Co ions due to the Fe ion implantation. In $\mathrm{CoSb}_{3}$, the lowest unoccupied states near the Fermi level are composed of Co $3 \mathrm{~d}$ and $\mathrm{Sb} 5 \mathrm{p}$ states, and the electrons from these unoccupied states take part in the transport process. Hence, the decrease in resistivity and increase in the Seebeck coefficient for the $\mathrm{I}_{2.5 \mathrm{E} 15} \mathrm{~A}$ sample as compared to $\mathrm{P}$ may be attributed to the change in the density of the states contributed by the Co $3 d$ to Sb 5p states. Fig. 11 shows the XANES spectra at the Fe K-edge of the Fe-implanted $\mathrm{CoSb}_{3}$ samples. The XANES pre-edge spectra were analysed by linking spectra from the $\mathrm{Fe}$ implanted samples with those from $\mathrm{Fe}_{2} \mathrm{O}_{3}$ and $\mathrm{Fe}$ foil. The weak pre-edge peak at $\sim 7115 \mathrm{eV}$ corresponds to the atomic-like transition from the core 1 s orbital to the $3 \mathrm{~d}$ empty states. The main peaks between 7133 and $7139 \mathrm{eV}$ are associated with a transition from the core $1 \mathrm{~s}$ orbital to empty $4 \mathrm{p}$ states. ${ }^{53}$ The spectral shape of the $\mathrm{I}_{1 \mathrm{E} 15} \mathrm{~A}$ sample lies at a lower binding energy compared to the samples implanted at higher fluence. The intensity of the main absorption peak at $7133 \mathrm{eV}$ decreases with increasing ion fluence. An additional peak at $7147 \mathrm{eV}$ is also observed in all samples. The pre-edge structure in the XANES spectra of the transition metal Fe K-edge is ascribed to quadrupolar transitions from the core $1 \mathrm{~s}$ orbital to $3 \mathrm{~d}$ empty orbitals (dipole forbidden in an ideal octahedron), the transition of the $3 \mathrm{~d}-4 \mathrm{p}$ mixing of Co (dipole allowed) and the $3 \mathrm{~d}-\mathrm{p}$ mixing between the Co atom and $\mathrm{Sb} .^{54}$

Therefore, the positions of the splitting of the pre-edge peaks directly reflect the crystal field splitting of the $3 \mathrm{~d}$ orbital subbands. For octahedral coordination, the peaks are associated with the $t_{2 g}$ and $e_{g}$ transitions. For tetrahedral coordination, the crystal field splitting with the $t_{2 g}$ and $e_{g}$ levels is much less and not resolvable into different peaks, so these appear as a single peak. Hence, there is a change in the shape of the pre-edge split peak into a normal singlet peak as the oxidation state changes

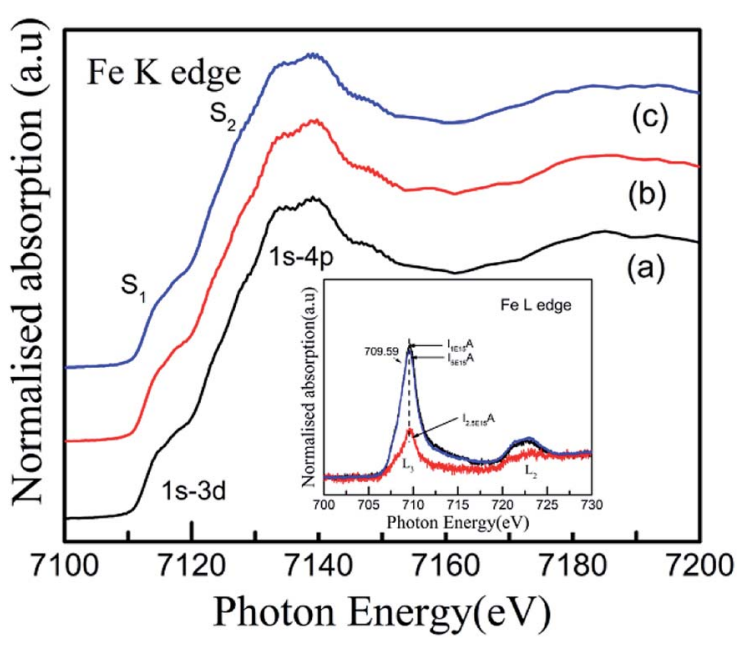

Fig. 11 Fe K-edge XANES spectra of (a) $I_{1 E 15} A$, (b) $I_{2.5 E 15} A$, and (c) $I_{5 E 15} A$ thin films. Inset shows the $\mathrm{Fe} \mathrm{L}_{3,2}$-edges XANES spectra of the $\mathrm{Fe}$ implanted $\mathrm{CoSb}_{3}$ thin films. from a $\mathrm{Fe}^{3+}$ octahedral to a $\mathrm{Fe}^{2+}$ tetrahedral structure. In the present study, the oxidation state for all implanted samples is the $3+$ octahedral state. Also, from the small pre-edge feature appearing between $7133 \mathrm{eV}$ and $7138 \mathrm{eV}$, it can be anticipated that a slightly distorted $\mathrm{FeSb}_{6}$ octahedron is present, indicating that some of the implanted Fe ions substitute Co in the $\mathrm{CoSb}_{6}$ octahedron. Fig. 11 (inset) shows the $\mathrm{Fe} \mathrm{L}_{3}$-edge of the Feimplanted $\mathrm{CoSb}_{3}$ thin films. For divalent iron, the $\mathrm{Fe} \mathrm{L}_{3}$-edge spectra are dominated by a sharp peak at $707.8 \mathrm{eV}$, along with a broader and less intense peak at $710.5 \mathrm{eV}$. For trivalent iron, the $\mathrm{L}_{3}$-edge is depicted by a sharp peak at $709 \mathrm{eV}$ and a less intense shoulder at $707.8 \mathrm{eV} .^{55}$ The spectra show the $\mathrm{Fe}_{3}$-edge at $709.59 \mathrm{eV}$ and a small shoulder at $707 \mathrm{eV}$. The spectra of the Fe $\mathrm{L}_{3}$-edge of the present study resemble that of the $\mathrm{Fe}^{3+}$ species. ${ }^{55}$ Hence, the Fe ion is implanted in $\mathrm{CoSb}_{3}$ in the $\mathrm{Fe}^{3+}$ state, which is also confirmed by the Fe K-edge absorption spectra. The pre-edge appears at $7115 \mathrm{eV}$ for the Fe(III) species (as in $\mathrm{Fe}_{2} \mathrm{O}_{3}$ ), and at $7112.5 \mathrm{eV}$ for the $\mathrm{Fe}$ (II) species (as in $\mathrm{Fe}$ (II) acetate).$^{56}$ Comparing the pre-edge and main absorption edge features with that of the $\mathrm{Fe}_{\text {foil }}{ }^{57}$ and reference iron oxides from literature, these spectra resemble that of the $\mathrm{Fe}_{2} \mathrm{O}_{3}$ haematite. ${ }^{56}$ The absorption pre-edge for all samples appears at $7115 \mathrm{eV}$, indicating the presence of the $\mathrm{Fe}^{3+}$ species. This is also confirmed from the Fe L-edge spectra. Fig. 12 shows the schematic reflecting the structural modifications due to $\mathrm{Fe}$ ion implantations in the $\mathrm{CoSb}_{3}$.

The electrical resistivity decreases substantially after Fe doping, indicating that the Fe ions are electrically active and act as an electron acceptor. This is further confirmed with the changing of the sign of $S$ from a negative value to a positive one after Fe ion implantation. Yang et al. ${ }^{23}$ reported that the hole concentration increases at a rate of $\sim 0.03$ holes per Fe ion, and concluded that the $\mathrm{Fe}$ ions substitute $\mathrm{Co}$ in a low spin $\mathrm{d}^{5}$ configuration in the $\mathrm{CoSb}_{3}$ lattice in a trivalent state. Similarly, it can be concluded from the XAS results that the implanted Fe is in the $3+$ state. For the implanted samples, the decrease in resistivity is due to the addition of p-type charge carriers. It is observed that the $S$ value decreases with the increase in Fe ion fluence. The lowest fluence $\left(\mathrm{I}_{1 \mathrm{E} 15} \mathrm{~A}\right)$ has the highest $S$ value within the complete temperature range. The positive $S$ value follows the relation: ${ }^{58}$

$$
S_{\mathrm{p}}=\frac{\left(E_{\mathrm{V}}-E_{\mathrm{F}}\right)}{e T}+\frac{2 k_{\mathrm{B}}}{e}
$$

where $E_{\mathrm{V}}$ is the minimum of the valence band, $E_{\mathrm{F}}$ is the Fermi level, $e$ is the charge of the carrier, $k_{\mathrm{B}}$ is the Boltzmann constant, and $T$ is the absolute temperature. The $S$ value varies mainly due to the changes in the Fermi level. Due to the doping of Fe ions, the hole carrier concentration increases and shifts the Fermi level towards the valence band; hence, the $S$ value is positive. In another literature, ${ }^{\mathbf{1 1}}$ it is explained that $S$ is enhanced by $\mathrm{Ni}$ ion implantation on the basis of changes in the density of states. Katsuyama et al. ${ }^{59}$ reported that $\mathrm{FeSb}_{2}$ and $\mathrm{CoSb}_{3}$ form a solid solution. They showed that the electrical resistivity increases and $S$ decreases due to the presence of $\mathrm{FeSb}_{2}$ particles. This is consistent with the present study. 

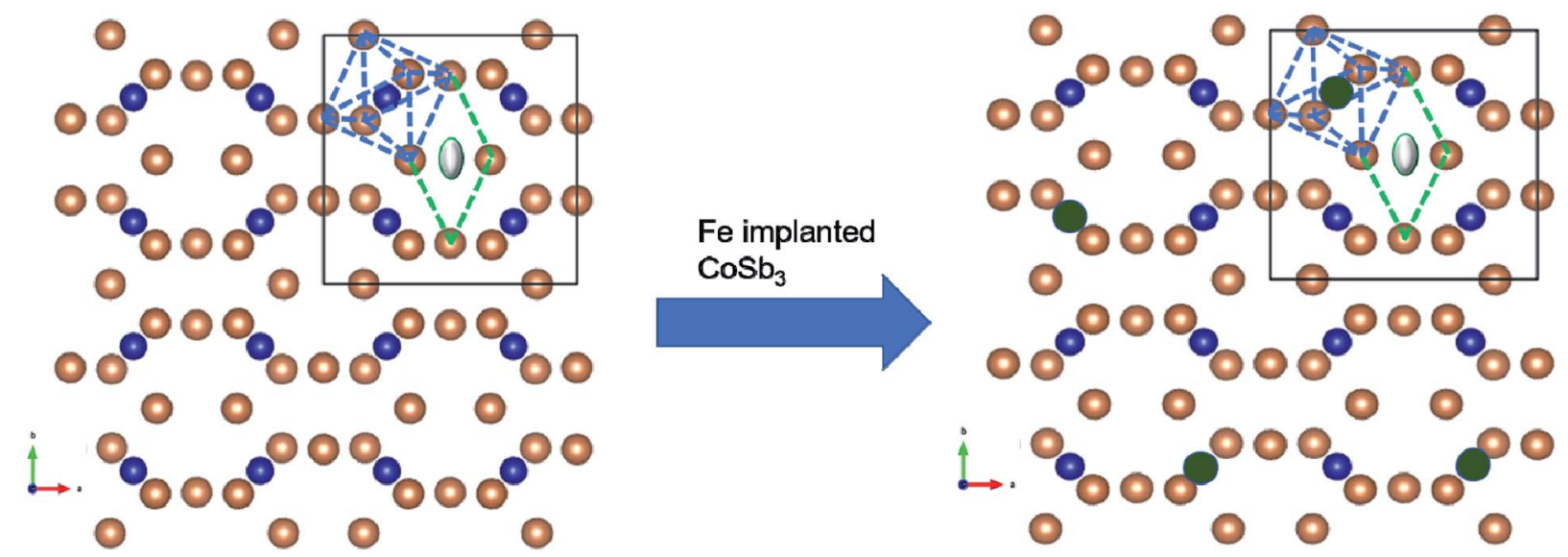

Fig. 12 Crystal structure of $\mathrm{CoSb}_{3}$. Structure with blue dashed lines forms the $\mathrm{CoSb}_{6}$ octahedra and the one with the green dashed lines depicts the void. Brown-coloured atoms are of Sb, blue ones are of $\mathrm{Co}$ and grey-coloured atom shows the guest atom (left). The image (right side) shows the Fe-implanted skutterudite with the Co atom substituted with the Fe atom (green-coloured).

\section{Conclusion}

Polycrystalline $\mathrm{CoSb}_{3}$ thin films with the skutterudite structure were deposited by PLD onto a Si(100) substrate and investigated for their structural, optical, and morphological properties due to Fe ion implantation after RTA. The Fe ion implantation of energy at $120 \mathrm{keV}$ led to the amorphization of films that regained their crystallinity after the RTA process at $873 \mathrm{~K}$. Five out of eight Raman active modes are seen in the samples of PA, $\mathrm{I}_{1 \mathrm{E} 15} \mathrm{~A}$, and $\mathrm{I}_{5 \mathrm{E} 15} \mathrm{~A}$, which are absent in the $\mathrm{P}$ film, depicting the perfect cubic structure of the as-deposited film. The lattice parameter of the highest-fluence-implanted annealed film is found to correspond to that of the bulk material $(9.035 \AA$ ). The sign of $S$ changes from negative to positive with Fe doping, giving the highest value of $S=245 \mu \mathrm{V} \mathrm{K}^{-1}$ for $\mathrm{I}_{1 \mathrm{E} 15} \mathrm{~A}$ at $400 \mathrm{~K}$ and the highest value of P.F. $\left(700 \mu \mathrm{W} \mathrm{m} \mathrm{m}^{-1} \mathrm{~K}^{-2}\right)$. The Fe substitution on the Co site leads to the creation of vacancies, which gives rise to a high concentration of holes. The high Seebeck coefficient and reduced electrical resistivity of the Fe-implanted sample leads to a high power factor. Fe L-edge XANES spectra show that Fe occupies the Co site in the trivalent state. By optimising the parameter of implantation, $\mathrm{CoSb}_{3}$ might lead to advanced thermoelectric applications.

\section{Conflicts of interest}

There are no conflicts to declare.

\section{Acknowledgements}

The authors (K. A. and A. M.) would like thank the Indo-Taiwan Bilateral Project (Project no.: GITA/DST/TWN/P-64/2015) under the GITA-Department of Science and Technology for providing financial support, including a research fellowship. C. L. D acknowledges both the Taiwan-Indo project of MoST contract number (MoST 104-2923-M-032-001-MY3) and also the Taiwan Experience Education Programs (TEEP) of MoE. We are grateful to Mr Sunil Ojha, Ms Devarani, and Dr Fouran Singh for their help in carrying out the RBS studies, ion implantation, the Raman measurements and research discussions. The authors also thank MRC, MNIT Jaipur for AFM measurements.

\section{References}

1 M. Rull-Bravo, A. Moure, J. F. Fernández and M. MartínGonzález, RSC Adv., 2015, 5, 41653-41667.

2 G. S. Nolas, D. T. Morelli and T. M. Tritt, Annu. Rev. Mater. Sci., 1999, 29, 89-116.

3 M. V. Daniel, M. Lindorf and M. Albrecht, J. Appl. Phys., 2016, 120, 125306-125311.

4 G. S. Nolas, J. Yang and H. Takizawa, Appl. Phys. Lett., 2004, 84, 5210-5212.

5 E. Z. Kurmaev, A. Moewes, I. R. Shein, L. D. Finkelstein, A. L. Ivanovskii and H. Anno, J. Phys.: Condens. Matter, 2004, 16, 979-987.

6 G. S. Nolas, J. L. Cohn and G. A. Slack, Phys. Rev. B, 1998, 58, 164-170.

7 K.-H. Park, S. Lee, W.-S. Seo, S. Baek, D.-K. Shin and I.-H. Kim, J. Korean Phys. Soc., 2014, 64, 1004-1008.

8 Z. G. Chen, G. Hana, L. Yanga, L. Cheng and J. Zou, Prog. Nat. Sci.: Mater. Int., 2012, 22, 535-549.

9 L. Bertini, C. Stiewe, M. Toprak, S. Williams, D. Platzek, A. Mrotzek, Y. Zhang, C. Gatti, E. Müller, M. Muhammed and M. Rowe, J. Appl. Phys., 2003, 93, 438-447.

10 Q. Shen, J. Li and L. Zhang, Sol. Energy Mater. Sol. Cells, 2000, 62, 167-172.

11 M. Bala, A. Masarrat, A. Bhogra, R. C. Meena, Y. Lu, Y. Huang, C. Chen, C. Dong, S. Ojha, D. K. Avasthi, S. Annapoorni and K. Asokan, ACS Appl. Energy Mater., 2018, 4-11.

12 M. Bala, A. Bhogra, S. A. Khan, T. S. Tripathi, S. K. Tripathi, D. K. Avasthi and K. Asokan, J. Appl. Phys., 2017, 121, 215301-215309.

13 J. Peng, J. Yang, X. Song, Y. Chen, S. Bao and T. Zhang, Front. Mater. Sci. China, 2007, 1, 177-180. 
14 B. Schüpp, I. Bächer, M. Hecker, N. Mattern, V. Savchuk and J. Schumann, Thin Solid Films, 2003, 434, 75-81.

15 K. H. Park and I. H. Kim, Mater. Sci. Forum, 2011, 695, 65-68. 16 X. Zhang, Q. M. Lu, J. X. Zhang, Q. Wei, D. M. Liu and Y. Q. Liu, J. Alloys Compd., 2008, 457, 368-371.

17 G. A. Lamberton Jr, S. Bhattacharya, R. T. Littleton IV, M. A. Kaeser, R. H. Tedstrom, T. M. Tritt, J. Yang and G. S. Nolas, Appl. Phys. Lett., 2002, 80, 598-600.

18 X. Shi, S. Bai, L. Xi, J. Yang, W. Zhang, L. Chen and J. Yang, J. Mater. Res., 2011, 26, 1745-1754.

19 G. Meisner, D. Morelli, S. Hu, J. Yang and C. Uher, Phys. Rev. Lett., 1998, 80, 3551-3554.

20 G. S. Nolas, M. Kaeser, R. T. Littleton and T. M. Tritt, Appl. Phys. Lett., 2000, 77, 1855-1857.

21 S. Wang, J. R. Salvador, J. Yang, P. Wei, B. Duan and J. Yang, NPG Asia Mater., 2016, 8, e285.

22 X. Shi, J. Yang, J. R. Salvador, M. F. Chi, J. Y. Cho, H. Wang, S. Q. Bai, J. H. Yang, W. Q. Zhang and L. D. Chen, J. Am. Chem. Soc., 2011, 133, 7837-7846.

23 J. Yang, G. P. Meisner, D. T. Morelli and C. Uher, Phys. Rev. B, 2000, 63, 1-11.

24 S. Katsuyama, Y. Shichijo, M. Ito, K. Majima and H. Nagai, J. Appl. Phys., 1998, 84, 6708-6712.

25 Il-Ho Kim and S-C. Ur, Mater. Lett., 2007, 61, 2446-2450.

26 V. Savchuk, A. Boulouz, S. Chakraborty, J. Schumann and H. Vinzelberg, J. Appl. Phys., 2002, 92, 5319-5326.

27 M. V. Daniel, C. Brombacher, G. Beddies, N. Jöhrmann, M. Hietschold, D. C. Johnson, Z. Aabdin, N. Peranio, O. Eibl and M. Albrecht, J. Alloys Compd., 2015, 624, 216-225.

28 S. R. Sarath Kumar, A. Alyamani, J. W. Graff, T. M. Tritt and H. N. Alshareef, J. Mater. Res., 2011, 26, 1836-1841.

29 S. R. S. Kumar, D. Cha and H. N. Alshareef, J. Appl. Phys., 2011, 110, 083710.

30 S. Yadav, S. Chaudhary and D. K. Pandya, Appl. Surf. Sci., 2018, 435, 1265-1272.

31 L. Kumari, W. Li, J. Y. Huang and P. P. Provencio, Nanoscale Res. Lett., 2010, 5, 1698-1705.

32 H. Anno, T. Sakakibara, Y. Notohara, H. Tashiro, T. Koyanagi, H. Kaneko and K. Matsubara, XVI ICT'97, Proc. ICT'97, 16th Int. Conf. Thermoelectr. (Cat. No.97TH8291), 1997, vol. 81, pp. 338-342.

33 A. Ahmed and S. Han, Appl. Surf. Sci., 2017, 408, 88-95.

34 S. R. Sarath Kumar, D. Cha and H. N. Alshareef, J. Appl. Phys., 2011, 110, 083710.

35 J. C. Caylor, A. M. Stacy, R. Gronsky and T. Sands, J. Appl. Phys., 2001, 89, 3508-3513.

36 A. Dauscher, M. Puyet, B. Lenoir, D. Colceag and M. Dinescu, Appl. Phys. A, 2004, 79, 1465-1468.

37 D. Colceag, A. Dauscher, B. Lenoir, V. Da Ros, R. Birjega, A. Moldovan and M. Dinescu, Appl. Surf. Sci., 2007, 253, 8097-8101.

38 T. S. Tripathi, M. Bala and K. Asokan, Rev. Sci. Instrum., 2014, 85, 085115.
39 W. Möller and W. Eckstein, Nucl. Instrum. Methods Phys. Res., Sect. B, 1984, 814-818.

40 E. N. M. Christensen, B. B. Iversen, L. Bertini, C. Gatti, M. Toprak and M. Muhammed, J. Appl. Phys., 2004, 96, 3148-3157.

41 K. Momma and F. Izumi, J. Appl. Crystallogr., 2011, 44, 12721276.

42 P. Wei, W. Zhao, D. Tang, W. Zhu, X. Nie and Q. Zhang, J. Mater., 2016, 2, 280-289.

43 G. S. Nolas, C. A. Kendziora and H. Takizawa, J. Appl. Phys., 2003, 94, 7440-7444.

44 J. L. Feldman and D. J. Singh, Phys. Rev. B, 1996, 53, 62736282.

45 J. F. Ziegler, M. D. Ziegler and J. P. Biersack, Nucl. Instrum. Methods Phys. Res., Sect. B, 2010, 268, 1818-1823.

46 T. Caillat, A. Borshchevsky and J.-P. Fleurial, J. Appl. Phys., 1996, 80, 4442-4449.

47 M. Bala, S. Gupta, S. K. Srivastava, S. Amrithapandian, T. S. Tripathi, S. K. Tripathi, C. Dong, C. Chen, D. K. Avasthi and K. Asokan, Phys. Chem. Chem. Phys., 2017, 19, 24886-24895.

48 J. W. Sharp, E. C. Jones, R. K. Williams, P. M. Martin and B. C. Sales, J. Appl. Phys., 1995, 78, 1013-1018.

49 C.-J. Liu, J.-L. Chen, L.-C. Huang, Z.-R. Lin and C.-L. Chang, J. Appl. Phys., 2007, 102, 014908.

50 S. Y. Istomin, O. A. Tyablikov, S. M. Kazakov, E. V Antipov, A. I. Kurbakov, A. A. Tsirlin, N. Hollmann, Y. Y. Chin, H. Lin, C. T. Chen, A. Tanaka, L. H. Tjeng and Z. Hu, Dalton Trans., 2015, 44, 10708-10713.

51 T. Burnus, Z. Hu, M. W. Haverkort, J. C. Cezar, D. Flahaut, V. Hardy, A. Maignan, N. B. Brookes, A. Tanaka, H. H. Hsieh, H.-J. Lin, C. T. Chen and L. H. Tjeng, Phys. Rev. B: Condens. Matter Mater. Phys., 2006, 74, 245111245115.

52 D. F. Franco, H. Fares, A. E. De Souza, S. H. Santagneli and M. Nalin, Ecletica Quim. J., 2017, 42, 51-59.

53 M. G. Kim, H. S. Cho and C. H. Yo, J. Phys. Chem. Solids, 1998, 59, 1369-1381.

54 T. Yamamoto, X-Ray Spectrom., 2008, 37, 572-584.

55 P. A. van Aken, B. Liebscher and V. J. Styrsa, Phys. Chem. Miner., 1998, 4, 323-327.

56 C. Genovese, M. E. Schuster, E. K. Gibson, D. Gianolio, V. Posligua, R. Grau-crespo, G. Cibin, P. P. Wells, D. Garai, V. Solokha, S. K. Calderon, J. J. Velasco-velez, C. Ampelli, S. Perathoner, G. Held, G. Centi and R. Arrigo, Nat. Commun., 2018, 9, 1-12.

57 Z. Guo, L. L. Henry and E. J. Podlaha, J. Mater. Chem., 2005, 16, 1772-1777.

58 R. C. Mallik, R. Anbalagan, G. Rogl, E. Royanian, P. Heinrich, E. Bauer, P. Rogl and S. Suwas, Acta Mater., 2013, 61, 66986711.

59 S. Katsuyama, Y. Kanayama, M. Ito, K. Majima and H. Nagai, J. Appl. Phys., 2000, 88, 3484-3489. 